\title{
Al-Kamil fi-t-Ta'rix. Polnyj Svod Istorii. Trad. com. P. G. Bulgakov continuées par Š. S. Kamoliddin, Taškent, Uzbekistan, 2006, 559 p. [32] p. plates.
}

\author{
Étienne de La Vaissière
}

\section{(2) OpenEdition}

Journals

Édition électronique

URL : http://journals.openedition.org/abstractairanica/37806

DOI : 10.4000/abstractairanica.37806

ISSN : 1961-960X

Éditeur :

CNRS (UMR 7528 Mondes iraniens et indiens), Éditions de l'IFRI

Édition imprimée

Date de publication : 8 avril 2010

ISSN : 0240-8910

Référence électronique

Étienne de La Vaissière, "Al-Kamil fi-t-Ta'rix. Polnyj Svod Istorii. Trad. com. P. G. Bulgakov continuées par Š. S. Kamoliddin, Taškent, Uzbekistan, 2006, 559 p. [32] p. plates. », Abstracta Iranica [En ligne], Volume 30 | 2010, document 155, mis en ligne le 08 avril 2010, consulté le 01 octobre 2020. URL : http:// journals.openedition.org/abstractairanica/37806; DOI : https://doi.org/10.4000/abstractairanica. 37806

Ce document a été généré automatiquement le 1 octobre 2020.

Tous droits réservés 


\section{Al-Kamil fi-t-Ta'rix. Polnyj Svod Istorii. Trad. com. P. G. Bulgakov continuées par Š. S. Kamoliddin, Taškent, Uzbekistan, 2006, 559 p. [32] p. plates.}

Étienne de La Vaissière

Traduction des passages concernant l'Asie centrale de l'œuvre d'Ibn al-Atīir. C'est une source essentielle sur les Samanides et les Qarakhanides, après la fin de la chronique de Ṭabarī, mais les passages complétant Ṭabarī pour les périodes antérieures sont aussi traduits, allant ainsi de la mention de la bataille de Talas en 751 à l'an 1231. Le commentaire identifie personnes et lieux et donne les éventuelles variantes. L'ouvrage comprend un recueil d'illustrations (monnaies, cartes, miniatures), et plusieurs index.

INDEX

Thèmes : 4.2.2. Asie centrale

\section{AUTEURS}

ÉTIENNE DE LA VAISSIÈRE

EPHE - Paris 